Molecules 2000, 5, 746-755

molecules

ISSN 1420-3049

http://www.mdpi.org

\title{
Behaviour of Some Activated Nitriles Toward Barbituric Acid, Thiobarbituric Acid and 3-Methyl-1-Phenylpyrazol-5-one
}

\author{
H.M.F. Madkour*, M.R. Mahmoud, M.H. Nassar and M.M. Habashy \\ Synthetic Organic Chemistry Laboratory, Department of Chemistry, Faculty of Science, Ain Shams \\ University, Abbassiya, Cairo, Egypt
}

Fax: 00 2024831836, E-mail: hmfmadkour@hotmail.com

*Author to whom correspondence should be addressed.

Received: 6 September 1999; revised form: 15 December 1999/Accepted: 12 February 2000/Published: 20 May 2000

\begin{abstract}
The effect of some active methylene containing heterocyclic compounds, namely barbituric acid, thiobarbituric acid and 3-methyl-1-phenylpyrazol-5-one on $\alpha$-cyano-3,4,5trimethoxycinnamonitrile and ethyl $\alpha$-cyano-3,4,5-trimethoxycinnamate $(\mathbf{1 a}, \mathbf{b})$ was investigated. The structure of the new products was substantiated by their IR, ${ }^{1} \mathrm{H}-\mathrm{NMR}$ and mass spectra.
\end{abstract}

Keywords: Barbituric and thiobarbituric acids, pyrazolone, and activated nitriles.

\section{Introduction}

Recently, it has been reported that the reaction of chalcones with barbituric or thiobarbituric acid may afford pyranopyrimidine derivatives in the presence of $\mathrm{P}_{2} \mathrm{O}_{5}[1]$ or it may proceed via simple substitution with triethanolamine [2] depending on the reaction conditions. Also, the reaction of $\alpha$ cyanocinnamonitrile with barbituric acid afforded pyranopyrimidine [3], an arylidene derivative [4] or simple a substitution product [5]. The present work studies the behaviour of $\alpha$-cyano-cinnamonitrile derivatives 1a,b and chalcone $\mathbf{4}$ toward barbituric or thiobarbituric acid $\mathbf{2 a}, \mathbf{b}$. Thus, when compounds $\mathbf{1 a}, \mathbf{b}$ or compound $\mathbf{4}$ were reacted with compounds $\mathbf{2 a}, \mathbf{b}$ in refluxing pyridine they afforded the arylidine derivatives 3a,b [cf. Scheme 1].

(C) 2000 by MDPI (http://www.mdpi.org). Reproduction is permitted for noncommercial purposes. 


\section{Results and Discussion}

The proposed structures of compounds 3a,b were confirmed by ${ }^{1} \mathrm{H}-\mathrm{NMR}$, molecular weight determination using field desorption mass spectroscopy as well as the chemical evidence. The ${ }^{1} \mathrm{H}-\mathrm{NMR}$ spectrum of $3(\mathrm{Y}=\mathrm{O}, \mathrm{S})$ in DMSO-d $\mathrm{d}_{6}$ displayed signals from low to high field at $\delta$ (ppm) 11.5, 11.4 (two s, $2 \mathrm{H}, 2 \mathrm{NH}$ ), 8.4 (s,1H, olefinic proton), 7.9 (br.s, 2H, aromatic protons) and 3.95 (br. s, 9H, 3 $\mathrm{OMe}$ ) which agree well with the assigned structures.

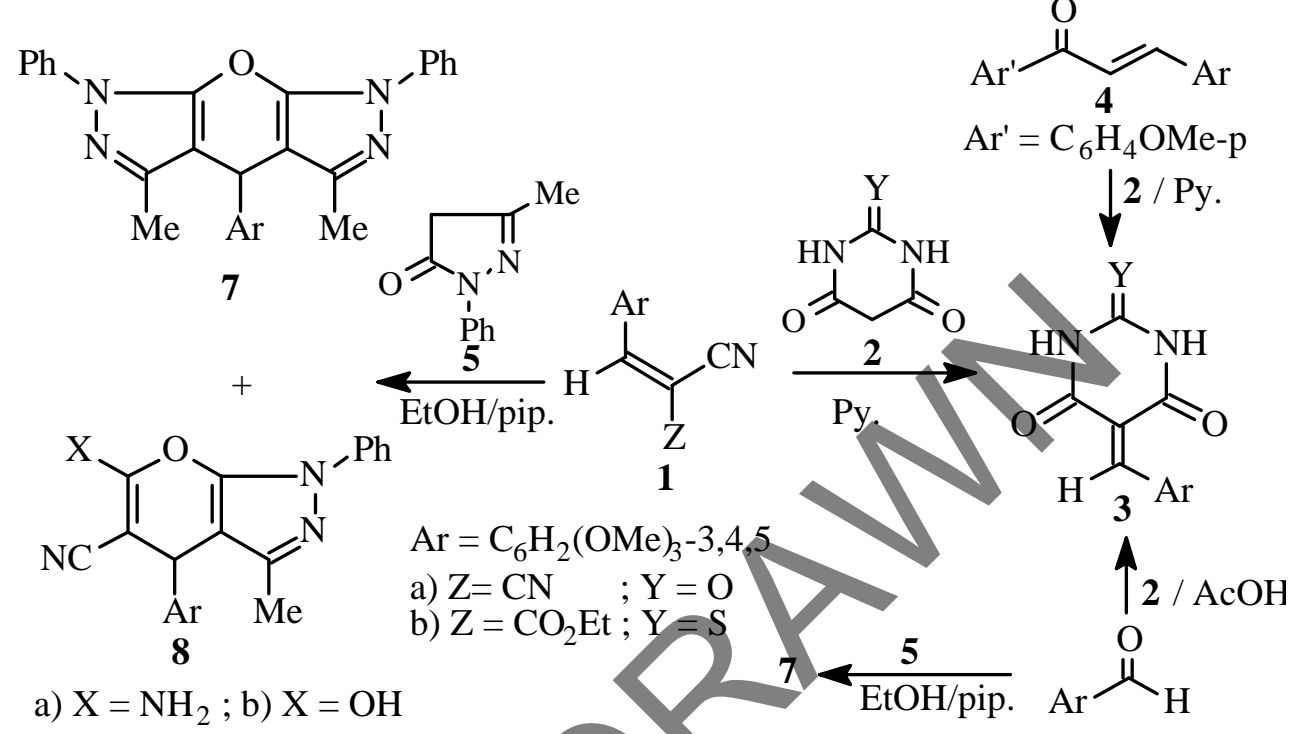

Scheme 1.

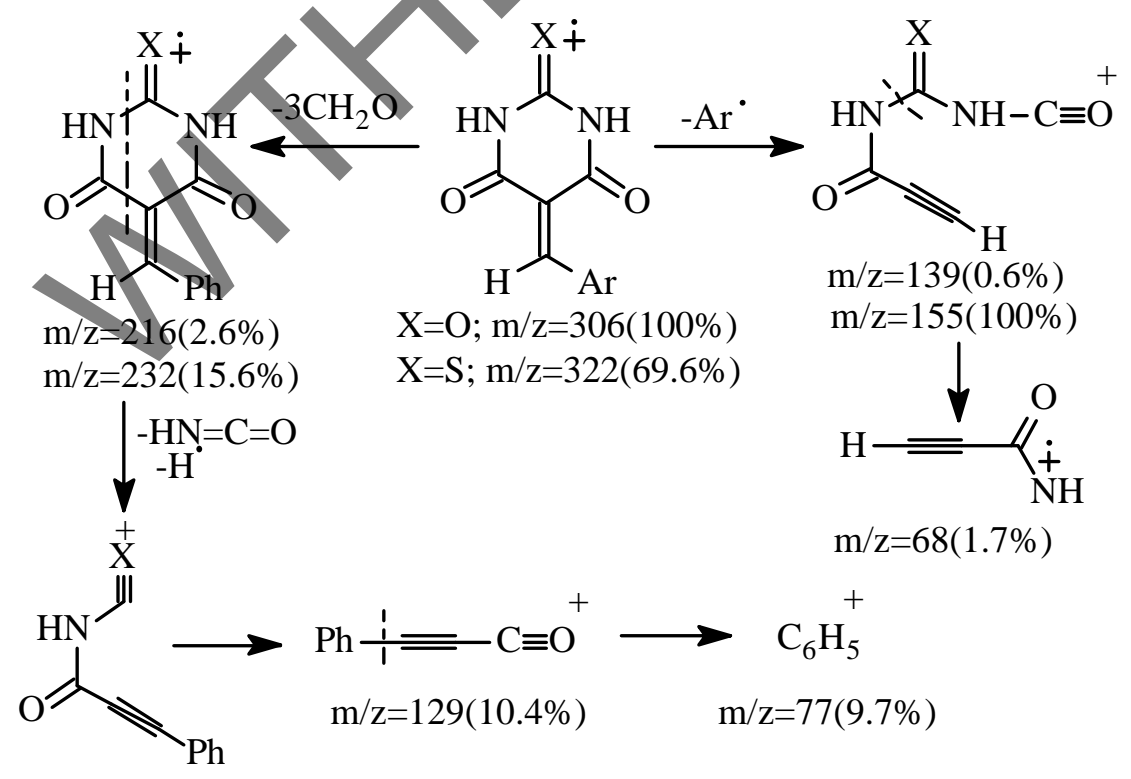

$\mathrm{m} / \mathrm{z}=172(1.6 \%)$

$\mathrm{m} / \mathrm{z}=188(10.4 \%)$

Figure 1. 
These structures are further supported by mass spectroscopy data. It was observed that their electron impact (EI) spectra have several common features, the first of which is that the highest recorded peak represents the corresponding molecular ion peaks $(\mathrm{m} / \mathrm{z} 306 \& 322)$. The second common feature is the similarity in their EI fragmentation patterns. The common fragmentation pathways are represented in Figure 1.

Furthermore, the arylidene derivatives 3a,b are identical (IR, TLC, m.p and mixed m.p) with an authentic sample prepared by stirring 3,4,5-trimethoxybenzaldehyde with barbituric and/or thiobarbituric acids in refluxing acetic acid. A possible pathway for the formation of the arylidene derivatives may be as represented in Scheme 2.

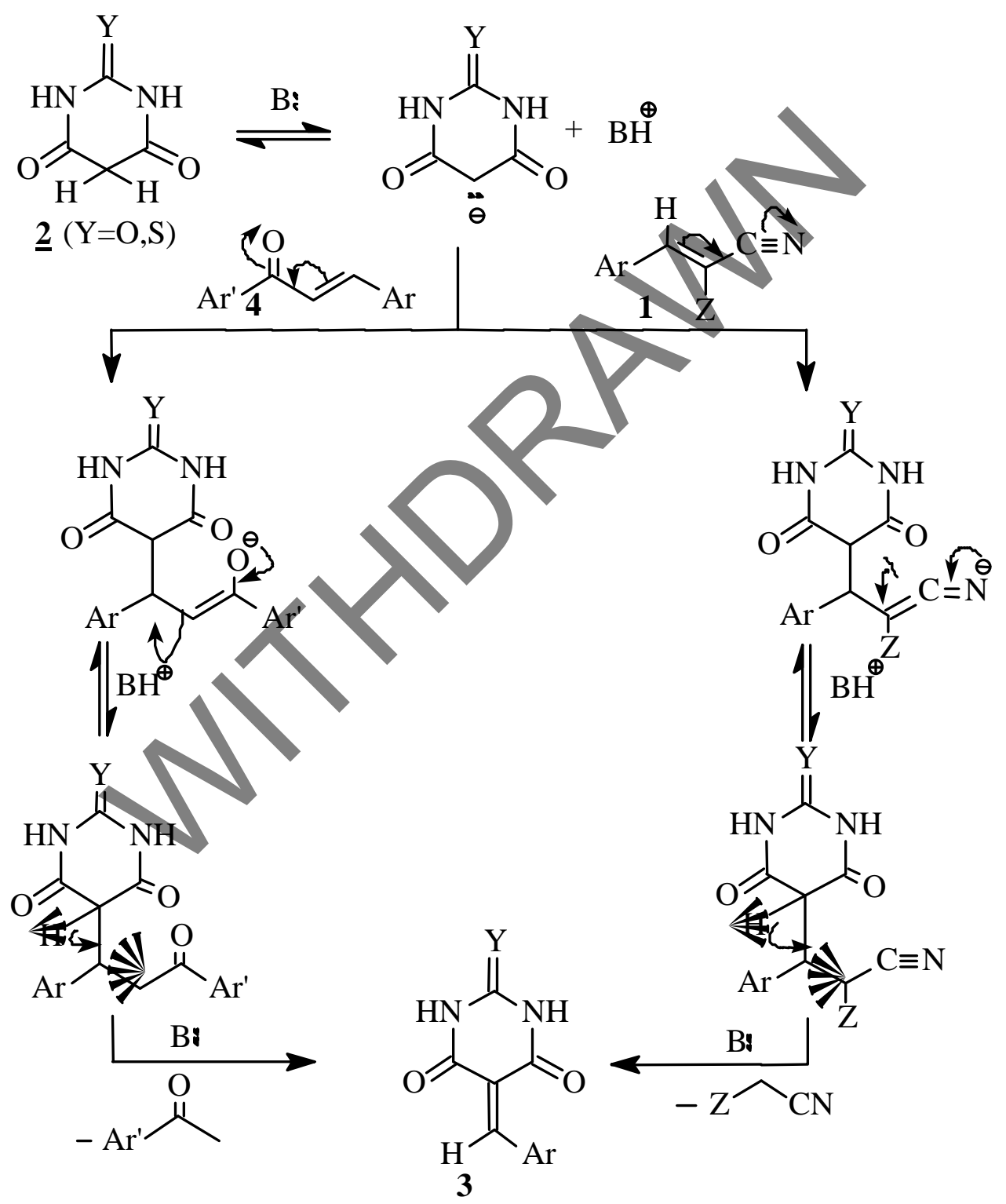

Scheme 2. 
The diverse biological activities of fused pyrazoles have stimulated considerable research in this field [6-11]. It has been reported [12] that the pyrazolone derivative 5 reacted with $\alpha$-cyanocinnamonitrile in the presence of piperidine to yield the 1:1 adduct $\mathbf{6}$. On the other hand, it has been also claimed [13] that the above mentioned reaction afforded two products instead of compound $\mathbf{6}$ [cf. Scheme 3].

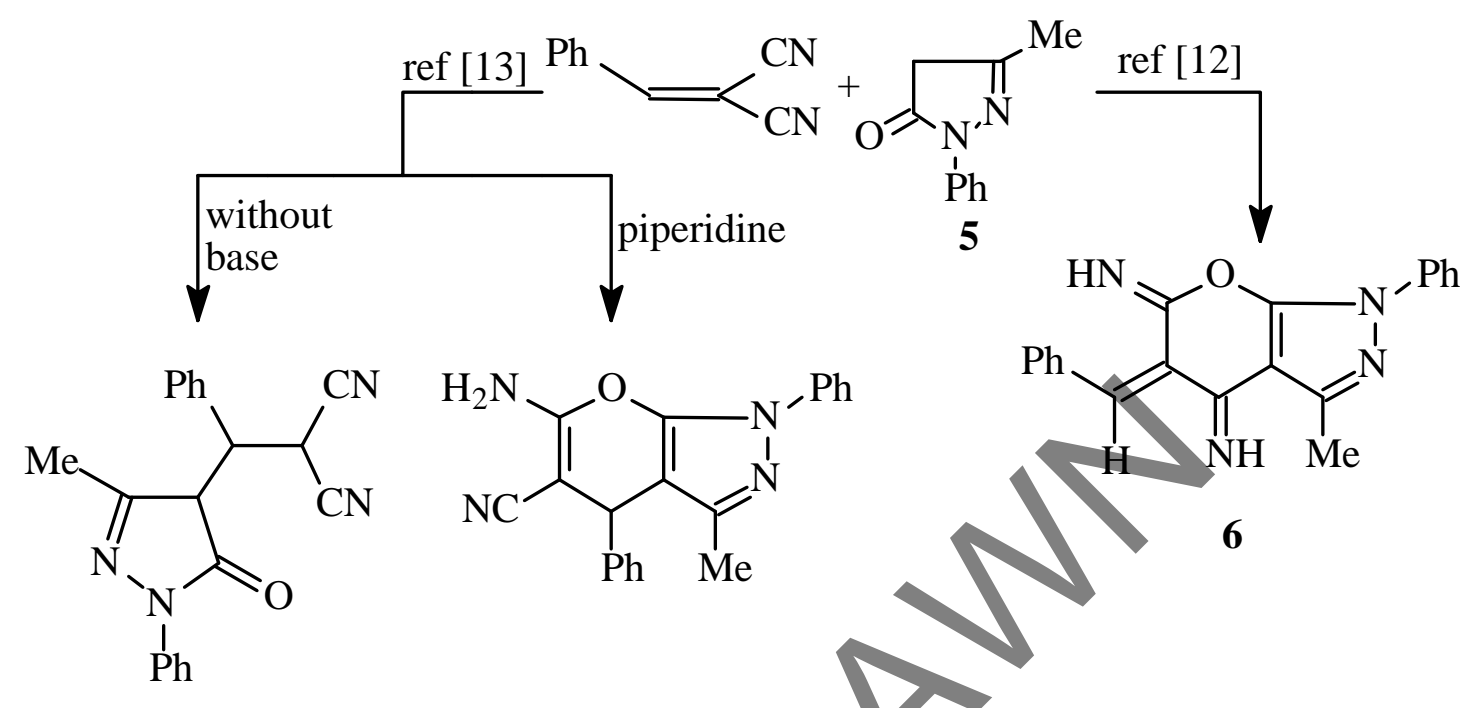

\section{Scheme 3.}

Because of the striking biological activity of fused pyrazoles and to extend the present work, equimolar amounts of 1a and 5 were refluxed in absolute ethanol in the presence of piperidine as a basic catalyst. After 15 minutes an insoluble fraction was isolated as colourless crystals (13\%) and identified as the oxinobispyrazole 7 . The reaction was then continued for $3 \mathrm{~h}$. Removal of most of the solvent and acidification with dilute acetic acid afforded the 1:1 adducts $\mathbf{8 a}$ and $\mathbf{8 b}$ as pale yellow crystals in $44 \%$ and $46 \%$ yield respectively [cf. Scheme 1]. The structure of 7 was elucidated exclusively from its IR and mass spectral data beside the correct analytical data and chemical evidence. Thus, the IR spectrum of 7 lacks $v_{\mathrm{C}=\mathrm{O}}$ and $\mathrm{v}_{\mathrm{CN}}$. The mass spectrum of 7, which is represented in Figure 2, is in accordance with the proposed structure. Furthermore, the bispyrazole derivative 7 was identical (TLC, IR, m.p. and mixed m.p) with an authentic sample synthesized by stirring 3,4,5-trimethoxybenzaldehyde with 5 in absolute ethanol in the presence of a catalytic amount of piperidine for 15 minutes [cf. Scheme 1]. 


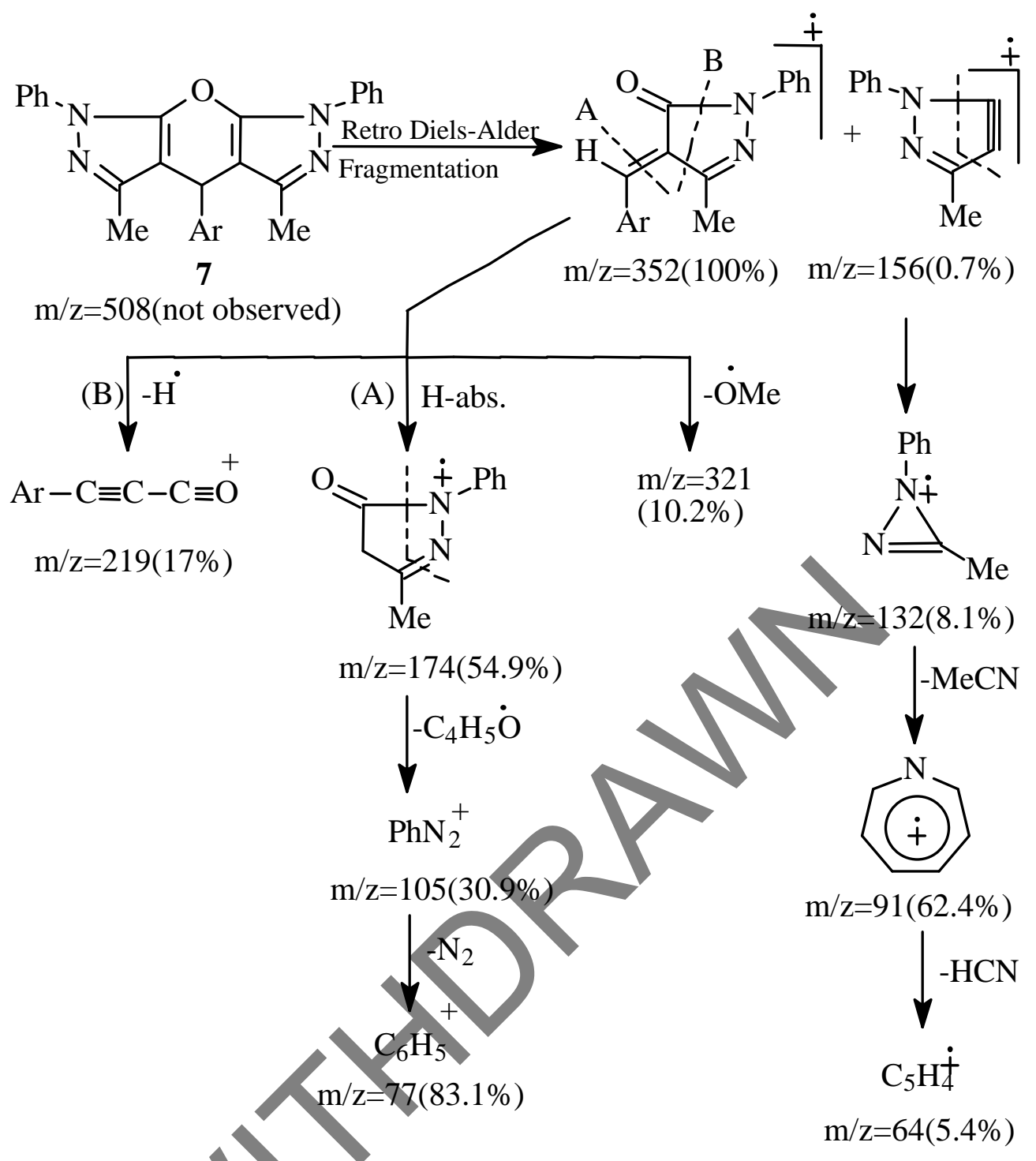

Figure 2.

The proposed structure of the adduct $\mathbf{8 a}$ is based upon:

i) A satisfactory elemental analysis.

ii) The IR displayed $v_{\mathrm{NH}_{2}}$ at 3485,3373 and $3223 \mathrm{~cm}^{-1}, v_{\mathrm{CN}}$ at $2205 \mathrm{~cm}^{-1}$ and $v_{\mathrm{C}=\mathrm{N}}$ at $1622 \mathrm{~cm}^{-1}$.

iii) The ${ }^{1} \mathrm{H}-\mathrm{NMR}$ spectrum (DMSO-d 6 ) exhibits signals at $\delta(\mathrm{ppm}) 7.9-7.3(\mathrm{~m}, 5 \mathrm{H}, \mathrm{Ph}), 6.8(\mathrm{~s}, 2 \mathrm{H}$, arom. protons), 5.0 (s, 1H, CHAr), 3.90-3.75 (two s, 9H ; 3OMe) and 2.3 (s, 3H, Me).

iv) EI fragmentation of $\mathbf{8 a}$ involves primary loss of $\mathrm{CN}^{\bullet}$ followed by $\mathrm{H}$-abstraction to give the radical cation of $\mathrm{m} / \mathrm{z}=393 / 100 \%$; base peak). There is also a loss of formaldehyde molecule to give the ion of $\mathrm{m} / \mathrm{z}=363(84.0 \%)$ which is the major daughter ion. Successive losses of two molecules of formaldehyde resulted in the radical cation of $\mathrm{m} / \mathrm{z}=303(5.1 \%)$. The tentative fragmentation pattern of $8 \mathbf{a}$ is represented in Figure 3. 
The IR spectrum of the adduct $\mathbf{8 b}$ lacks $v_{\mathrm{CO}}$ of ester and displayed $\mathrm{v}_{\mathrm{OH}}\left(\right.$ br) centered at $3913 \mathrm{~cm}^{-1}$, $v_{\mathrm{CH}} 2941 \mathrm{~cm}^{-1} v_{\mathrm{CN}}$ at $2216 \mathrm{~cm}^{-1}, v_{\mathrm{C}=\mathrm{N}}$ at $1620 \mathrm{~cm}^{-1}$ and $v_{\mathrm{C}=\mathrm{C}}$ at $1595 \mathrm{~cm}^{-1}$. The ${ }^{1} \mathrm{H}-\mathrm{NMR}$ spectrum of $\mathbf{8 b}\left(\mathrm{DMSO}_{6}\right)$ exhibits signals from low to high field at $\delta(\mathrm{ppm}) 7.9-7.4(\mathrm{~m}, 5 \mathrm{H}, \mathrm{ph}), 6.9(\mathrm{~s}$, $2 \mathrm{H}$, aromatic protons), 5.0 (s, 1H, CHAr), 4.0 - 3.8 (two s, 9H, $3 \mathrm{OMe}$ ). and 2.4 (s, 3H, Me). The mass spectrum of $\mathbf{8 b}$, which is in accord with the assigned structure, is represented in Figure 4.

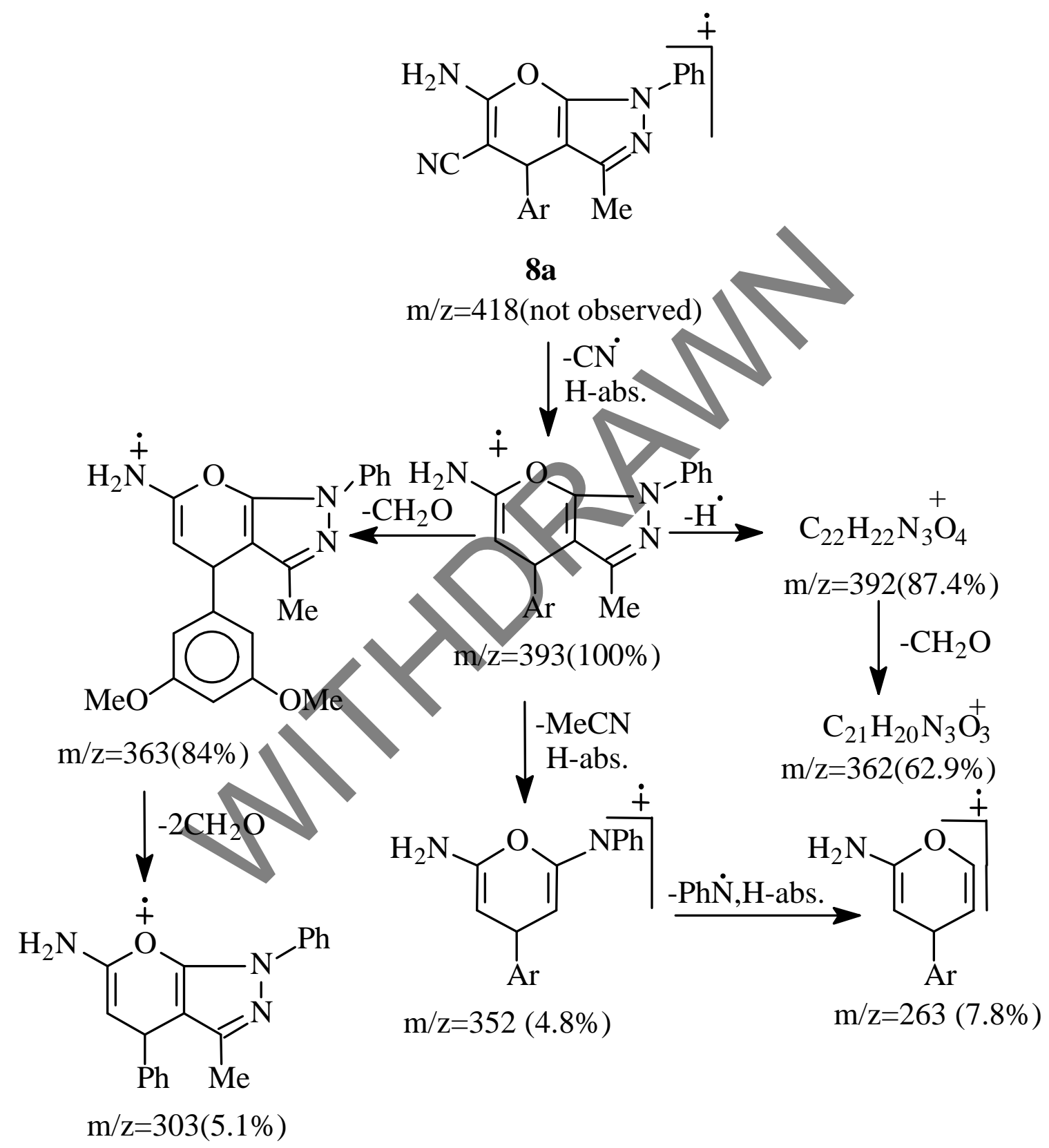

Figure 3. 
<smiles>Cc1nn(-c2ccccc2)c2c1C([Al])C=C(O)O2</smiles>

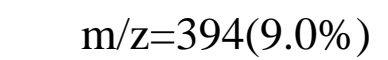

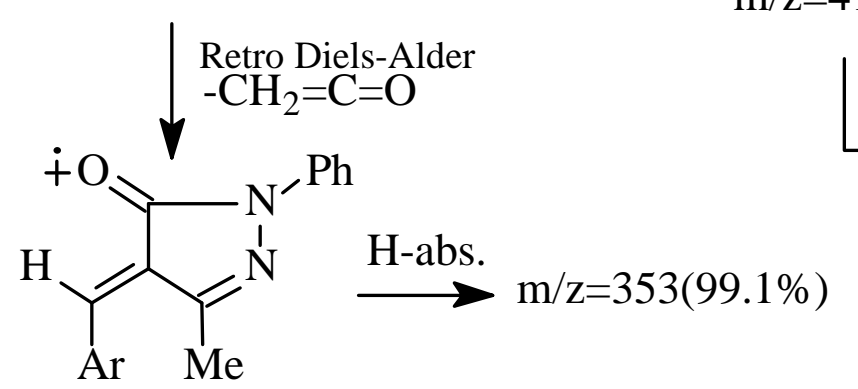

$\mathrm{m} / \mathrm{z}=352(100 \%)$<smiles></smiles>
$\mathrm{m} / \mathrm{z}=185(34.6 \%)$<smiles>CC(C)[C@H](C)C#N</smiles><smiles>CCC</smiles><smiles>Cc1nn(-c2ccccc2)c2c(C)c(C([Al])C#N)c(O)c(O)c12</smiles>

8b

$$
\mathrm{m} / \mathrm{z}=419(3.1 \%)
$$

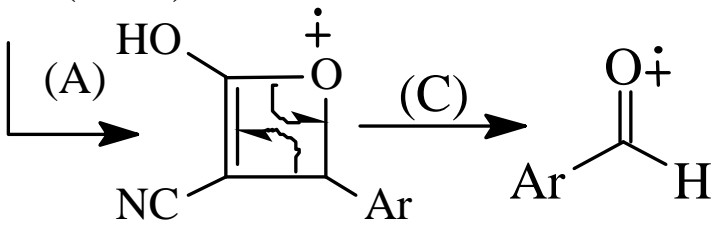

$$
\begin{array}{cc}
\mathrm{m} / \mathrm{z}=263(4.3 \%) & \mathrm{m} / \mathrm{z}=196(3.9 \%) \\
+ & \begin{array}{cc}
-\dot{\mathrm{OH}} & + \\
-\dot{\mathrm{C}} \mathrm{N} & -\mathrm{C} \equiv \mathrm{C}-\mathrm{OH} \\
\mathrm{m} / \mathrm{z}=67(2.1 \%)
\end{array}
\end{array}
$$

$$
\begin{aligned}
& \text { ( } \\
& \mathrm{C}_{6} \mathrm{H}_{5}^{+} \\
& \mathrm{Ph} \\
& \mathrm{m} / \mathrm{z}=77(61.3 \%) \\
& \mathrm{m} / \mathrm{z}=106(10.1 \%) \\
& \mathrm{m} / \mathrm{z}=196(3.9 \%)
\end{aligned}
$$

Figure 4.

The formation of the oxino bispyrazole derivative $\mathbf{7}$ from the reaction of $\mathbf{1 a}$ and/or $\mathbf{1 b}$ with 3methyl-1-phenylpyrazolone $\mathbf{5}$ probably proceeds via the initial Michael addition to afford an acyclic Michael adduct which then loses the active methylene moiety, i.e., malononitrile or ethyl cyanoacetate to give the arylidene pyrazolone which could be attacked by a new molecule of $\mathbf{5}$ followed by a cyclodehydration step to yield the isolated bispyrazole derivative 7 [cf. Scheme 4]. Cyclization of the acyclic Michael adducts via attack of the ring carbonyl either on the cyano or ester functional group yielded the products $\mathbf{8} \mathbf{a}$ and $\mathbf{8 b}$ respectively. 
<smiles>[Z]/C(C#N)=C\[In]</smiles>

5 acyclic Michael adduct

a) $\mathrm{Z}=\mathrm{CN}$; b) $\mathrm{Z}=\mathrm{CO}_{2} \mathrm{Et}$<smiles>[Z]C(C)[V]C(C)(Br)Br</smiles>

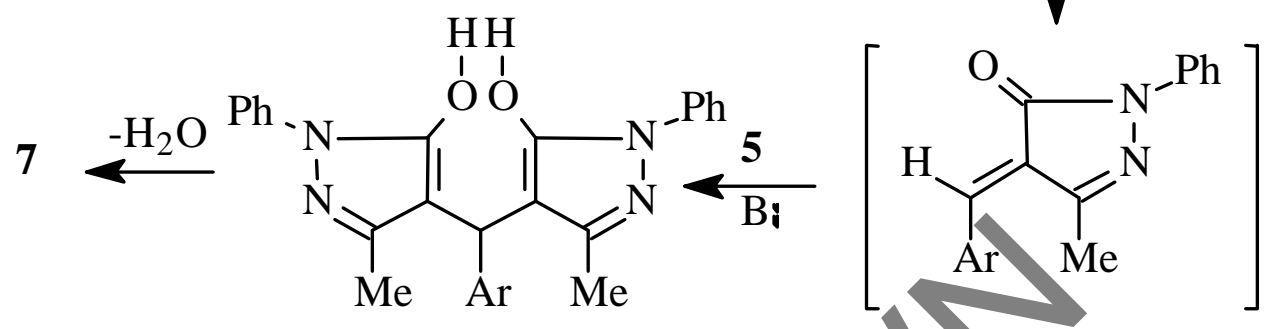

Scheme 4.

\section{Experimental}

\section{General}

Melting points are not corrected. The IR spectra were recorded in a Pye-Unicam SP 1200 spectrophotometer using the $\mathrm{KBr}$ wafer technique. The ${ }^{1} \mathrm{H}-\mathrm{NMR}$ spectra were recorded on a Varian GEMINI $200 \mathrm{MHz}$ NMR Spectrophotometer using DMSO-d 6 as solvent and TMS as internal standard. All chemical shifts are in ppm downfield from TMS. The elemental analysis were carried out in the Central Lab., Faculty of Science, Ain Shams University, Abbassiya, Cairo, Egypt. Mass spectra were recorded on Shimadzu GC-MS-QP 1000 EX instrument. The purity of the synthesised compounds was monitored by TLC.

Reaction of $\alpha$-cyano-3,4,5-trimethoxycinnamonitrile (1a) or ethyl $\alpha$-cyano-3,4,5-trimethoxycinnamate (1b) with barbituric acid or thiobarbituric acid; Formation of 5-(3,4,5-trimethoxybenzylidene)barbituric or thiobarbituric acid (3a or $\mathbf{3 b})$

A mixture of $1 \mathbf{a}(2.44 \mathrm{~g} ; 0.01 \mathrm{~mol})$ or $1 \mathbf{b}(2.91 \mathrm{~g}, 0.01 \mathrm{~mol})$ and barbituric acid $(1.28 \mathrm{~g}, 0.01 \mathrm{~mol})$ or thiobarbituric acid $(1.44 \mathrm{~g}, 0.01 \mathrm{~mol})$ in pyridine $(30 \mathrm{~mL})$ was refluxed for $3 \mathrm{~h}$. Most of the solvent was distilled off and the reaction mixture was cooled and acidified with ice-cold glacial acetic acid. The solid which deposited was filtered off, washed with cold water, dried and recrystallized from the proper solvent to give $\mathbf{3 a}$ or $\mathbf{3 b}$ [cf. Table 1]. 
Table 1. Physical characteristics of the new compounds.

\begin{tabular}{ccccccc}
\hline Compd. & Mol. Formula & $\begin{array}{c}\text { Mol. } \\
\text { Wt. }\end{array}$ & M.P $\left({ }^{\circ} \mathrm{C}\right)$ & Yield \% & $\begin{array}{c}\text { Recryst. } \\
\text { Solvent }\end{array}$ & Colour \\
\hline $\mathbf{3 a}$ & $\mathrm{C}_{14} \mathrm{H}_{14} \mathrm{~N}_{2} \mathrm{O}_{6}$ & 306 & $236-8$ & 78.6 & E.A & Yellow \\
\hline $\mathbf{3 b}$ & $\mathrm{C}_{14} \mathrm{H}_{14} \mathrm{~N}_{2} \mathrm{O}_{5} \mathrm{~S}$ & 322 & $196-8$ & 83.11 & $\mathrm{M}$ & Pink \\
\hline $\mathbf{7}$ & $\mathrm{C}_{30} \mathrm{H}_{28} \mathrm{~N}_{4} \mathrm{O}_{4}$ & 508 & $196-8$ & 13 & $\mathrm{CCl}_{4}$ & Colourless \\
\hline $\mathbf{8 a}$ & $\mathrm{C}_{23} \mathrm{H}_{22} \mathrm{H}_{4} \mathrm{O}_{4}$ & 418 & $170-2$ & 44 & $\mathrm{CCl}_{4}$ & Pale yellow \\
\hline $\mathbf{8 b}$ & $\mathrm{C}_{23} \mathrm{H}_{21} \mathrm{~N}_{3} \mathrm{O}_{5}$ & 419 & $204-6$ & 46 & B/L.p & Pale yellow \\
\hline
\end{tabular}

* All elemental analysis $(\mathrm{C}, \mathrm{H}, \mathrm{N})$ are in agreement with the calculated values.

** E.A. = Ethyl acetate , $\mathrm{M}=$ Methanol , B = Benzene. , L.p = Light petroleum.

Reaction of chalcone $\mathbf{4}$ with barbituric or thiobarbituric acid, Formation of $\mathbf{3 a}$ or $\mathbf{3 b}$

A mixture of chalcone $4(3.28 \mathrm{~g} ; 0.01 \mathrm{~mol})$. and barbituric acid $(1.28 \mathrm{~g}$; $0.01 \mathrm{~mol})$ or thiobarbituric acid $(1.44 \mathrm{~g}, 0.01 \mathrm{~mol})$ in pyridine $(30 \mathrm{~mL})$ was refluxed for $3 \mathrm{~h}$. The reaction mixture was concentrated, cooled, and acidified with ice cold acetic acid. The solid which separated out was filtered off, washed with water, dried and recrystallized from the suitable solvent to give $\mathbf{3 a}$ (26.7\% yield) or $\mathbf{3 b}$ (42.4\% yield).

Reaction of barbituric or thiobarbituric acid with 3,4,5-trimethoxybenzaldehyde; Formation of an authentic sample of $\mathbf{3 a}$

A mixture of barbituric acid $(1.28 \mathrm{~g} ; 0.01 \mathrm{~mol})$ or thiobarbituric acid $(1.44 \mathrm{~g} ; 0.01 \mathrm{~mol})$ and $3,4,5-$ trimethoxybenzaldehyde $(1.96 \mathrm{~g}, 0.01 \mathrm{~mol})$ in glacial acetic acid $(30 \mathrm{~mL})$ was heated under reflux for 30 minutes. The reaction mixture was concentrated, diluted with ice cold water. The solid deposited was filtered off, dried and recrystallized from the proper solvent to yield $\mathbf{3 a}(77.3 \%$ yield) or $\mathbf{3 b}$ (86.1\% yield).

Reaction of 1a or $\mathbf{1 b}$ with 3-methyl-1-phenylpyrazol-5-one (5); Formation of 4H-3,5-dimethyl-1,7diphenyl-4-(3,4,5-trimethoxy-phenyl)oxino[2,3-c:6,5-'c] bis-pyrazole (7) and 4H-6-amino-5-cyano-3methyl-1-phenyl-4-(3,4,5-trimethoxyphenyl)-pyrano[2,3-c]pyrazole (8a) or 4H-5-cyano-6-hydroxy-3methyl-1-phenyl-4-(3,4,5-trimethoxyphenyl)pyrano[2,3-c]-pyrazole (8b)

A mixture of the arylidene derivative $1 \mathbf{a}(2.4 \mathrm{~g} ; 0.01 \mathrm{~mol})$ or $\mathbf{1 b}(2.91 \mathrm{~g} ; 0.01 \mathrm{~mol})$ and 3-methyl-1phenylpyrazol-5-one $5(1.74 \mathrm{~g} ; 0.01 \mathrm{~mol})$ in absolute ethanol $(30 \mathrm{ml})$ was refluxed in the presence of a 
catalytic amount of piperidine. After 15 minutes, the colourless insoluble product was filtered off, dried and recrystallized from the proper solvent to give compound 7. The filtrate was refluxed up to 3h. Most of the solvent was distilled off and the reaction mixture was cooled and acidified with ice cold acetic acid. The deposited solid was filtered off, dried and recrystallized from the suitable solvent to give $\mathbf{8 a}$ or $\mathbf{8 b}$ [cf. Table 1].

Reaction of 5 with 3,4,5-trimethoxybenzaldehyde; Formation of an authentic sample of 7

A mixture of 3,4,5-trimethoxybenzaldehyde (1.96g; $0.01 \mathrm{~mol})$ and 3-methyl-1-phenylpyrazol-5-one (5) $(1.74 \mathrm{~g}, 0.01 \mathrm{~mol})$ in absolute ethanol $(30 \mathrm{~mL})$ was refluxed for 15 minutes in the presence of a catalytic amount of piperidine. The insoluble product was filtered off, dried and recrystallized from the appropriate solvent to give 7 .

\section{References and Notes}

1. Ahluwalia, V.; Kumar, K.; Alauddin, M.; Khandi, C.; Mallika N. Synth. Commun. 1990, 20(9), 1265.

2. Ahluwalia, V.K.; Aggarwal, R.; Alauddin, M.; Gill, G.; Khanduri, C.H. Heterocycles 1990, 31(1), 129-137.

3. Sharamin, Yu.A.; Klokol, G.V. J. Org. Chem. (USSR) 1984, 20, 2230-2233.

4. Abdel-Latif, F.F. Indian J. Chem. Sect. B. 1991, 30(3), 363-365.

5. Ibrahim,M.K.A.; El-Moghayar, M.R.H.; Sharaf,M.A.F. Indian J. Chem. Sect.B. 1987, 26, 216-219.

6. Koyama, G.; Umezawa, H. J. Antibiot. 1965, 18A, 175 (Chem. Abstr., 63, 15158d (1965)).

7. Robins, R. K.; Townsend, L. B.; Cassidy, F. C. Geroter, J. F.; Lewis, A. F.; Miller, R.L. J. Heterocycl. Chem. 1963, 3, 110.

8. El-Nagdi, M.H.; El-Moghayer, M.R.H.,El-Fahham, H.A.; Sallam, M.M.M.; Alnima, H.H. J. Heterocycl. Chem. 1980, 17, 209

9. El-Nagdi,M.H.; Fahmy, S.M;Hafez, E.A.A., El-Moghayer, M. R. H.; Amer, S.A.R. J. Heterocycl. Chem. 1979, 16, 1109

10. El-Nagdi, M.H.; Hafez, E.A.A., El-Fahham,H.A.; Kandeel, E.M. J. Heterocycl. Chem. 1980, $17,73$.

11. El-Nagdi, M.H.; El-Moghayer, M.R.H.; Fleita, D.H.; Hafez, E.A.A.; Fahmy, S.M. J. Org. Chem. 1976, 41, 3781.

12. Abdou, S.; Fahmy, S.M.; Sadek, K.U.; El-Nagdi, M.H. Heterocycles 1981, 16(12), 2177.

13. Sharamin, Yu.A.; Promonenkov, V. K. J. Org. Chem. (USSR) 1982, 18, 544-548.

Samples Availability: Available from the authors.

(C) 2000 by MDPI (http://www.mdpi.org). Reproduction is permitted for noncommercial purposes. 